\title{
Hydrodynamic Forces Generated on a Coarse Spherical Particle Beneath a Tidal Bore
}

\author{
Muhammad Zain Bin RIAZ ${ }^{\bowtie}$, Shu-Qing YANG, and Muttucumaru SIVAKUMAR \\ School of Civil, Mining and Environmental Engineering, University of Wollongong, NSW, Australia \\ $\triangle$ mzbr518@uowmail.edu.au
}

\begin{abstract}
The development of a bore in an open channel creates a sudden change in water surface elevation propagating upstream. In this study, physical modelling was performed to investigate both horizontal and vertical components of velocity and forces to clarify the mechanism of sediment initiation beneath a tidal bore. A laser Doppler anemometer, a highly sensitive force transducer, and ultrasonic displacement meters accompanied by video recordings were used to provide some quantitative data in terms of various force and velocity terms measured simultaneously acting on a targeted sphere. According to the experimental results, upward vertical force was the main force in destabilizing the particles however, a large upstream longitudinal force was found to be the dominant cause promoting upstream particle motion during the breaking roller passage. Furthermore, the forces were not only due to velocity but also to the sudden discontinuity in free water surface.
\end{abstract}

Keywords: tidal bore, drag force, lift force, laser Doppler anemometer, force transducer.

\section{INTRODUCTION}

It is common that when a tide starts to rise, a series of waves propagate upstream in some river mouths as a tidal bore. Some field observations and physical modelling highlighted that sediment incipient motion is likely to occur due to horizontal pressure gradient introduced by free stream velocity gradient (Foster et al. 2006; Frank et al. 2015). Khezri and Chanson (2015) investigated the incipient sediment motion beneath the tidal bore by estimating only the longitudinal forces that are responsible for sediment entrainment and took no account of the role of vertical forces. In waves, the vertical pressure gradient is mostly associated with variations in water depth. Whereas, how the uplift force caused by the vertical pressure gradient modifies sediment transport still needs to be investigated (Berni et al. 2017). The main aim of this study 
is to verify the newly designed experimental setup and relative impact of drag and lift force during a tidal bore.

\section{EXPERIMENTAL SETUP AND INSTRUMENTATION}

The experiments were conducted in a $10.5 \mathrm{~m}$ long, $0.4 \mathrm{~m}$ deep, and $0.3 \mathrm{~m}$ wide rectangular flume. The laser Doppler anemometer (LDA) was used to measure point velocity and turbulence. More detail of setup can be found in Yang et al. (2020) and Riaz et al. (2020). A highly sensitive force transducer was used to measure forces on the target sphere. A fast fully closing Tainter gate was installed at $x=10 \mathrm{~m}$ and a force transducer was fixed at $x=6 \mathrm{~m}$, where $x$ is the distance from the channel upstream inlet end. Two ultrasonic displacement meter were installed to measure water elevation fluctuation. Spheres of $38 \mathrm{~mm}$ average diameter were fixed by glue into a Perspex sheet in a hexagonal-shaped structure over a $10 \mathrm{~m}$ length of the flume. In the test section, a target sphere of $36.6 \mathrm{~mm}$ diameter was surrounded by a group of 3D printed spheres filled with small steel spheres which were not glued, in order to allow them to stay in place due to their own weight. Thus, the force sensor recorded the hydrodynamic forces on the sphere only due to water flow. All instruments were synchronized to within $\pm 0.5 \mathrm{~ms}$.

For all observations, the initial flow conditions were $Q=0.033 \mathrm{~m}^{3} / \mathrm{s}, h_{0}=0.135 \mathrm{~m}$, and $V_{0}=0.815 \mathrm{~m} / \mathrm{s}$ where $h_{0}$ and $V_{0}$ are the flow depth and depth averaged velocity. Videos were recorded between $x=6$ and $7 \mathrm{~m}$ with a handy camera Zoom ${ }^{\mathrm{TM}}(60 \mathrm{fps})$ for a tidal bore, for which the bore celerity was $U \approx 0.85 \mathrm{~m} / \mathrm{s}$, corresponding to a Froude number $=1.35$ to 1.45 .

\section{RESULTS AND DISCUSSION}

The water surface, instantaneous velocities and forces were measured over fixed rough bed. The propagation of breaking roller was linked with strong longitudinal deceleration and some negative instantaneous vertical velocities as reported by Reungoat et al. (2018) (see Fig. 1a). Two different trends of forces were observed. Stage 1 was the smooth rise of free surface (point 1) to the roller toe (point 2) while, roller toe to peak of the first wave crest (point 3) was stage 2 (Fig. 1). At stage 1 , lift force $(\approx 85 \%$ of submerged weight) was the predominant force however, behind the bore during stage 2 , the increasing trend of drag force (i.e., along the bore, upstream) had a significant role in maintaining motion and determining its extent. Both drag and lift forces acted on the particle in the negative direction due to flow reversal through transient recirculation and the sudden increase in free water surface at the arrival of the breaking
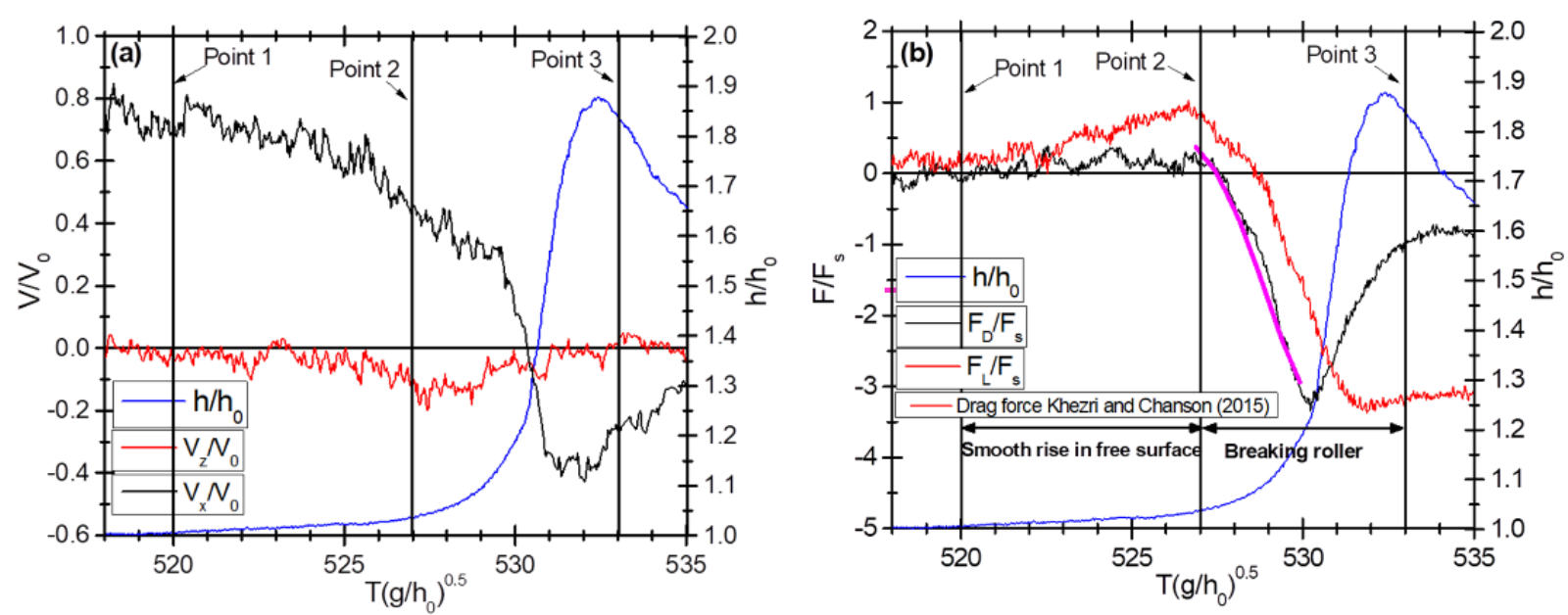

Fig. 1. Dimensionless Median EA water depth, horizontal velocity and vertical velocity, drag force and lift force beneath breaking bore at $x=6 \mathrm{~m}, z / h_{0}=0.037$. 
bore. The directly measured drag force findings were consistent with Khezri and Chanson's (2015) estimated drag force data (Fig. 1b). The forces acting on the target particle were median ensemble-averaged over 25 test runs to find the main trend, which is shown in Fig. 1b.

\section{CONCLUSION}

During the smooth rise of free-surface in a tidal breaking bore, the increase in forces indicates the importance of lift force which is necessary for particle movement. For the most part, drag force was the main influencing force prompting the inception of upstream particle motion.

A cknowledgments. The authors acknowledge the technical assistance of Gavin Bishop and Peter Ihnat (The University of Wollongong).

\section{References}

Berni, C., H. Michallet, and E. Barthélemy (2017), Effects of horizontal pressure gradients on bed destabilization under waves, J. Fluid Mech. 812, 721-751, DOI: 10.1017/jfm.2016.805.

Foster, D.L., A.J. Bowen, R.A. Holman, and P. Natoo (2006), Field evidence of pressure gradient induced incipient motion, J. Geophys. Res. Oceans 111, C05004, DOI: 10.1029/2004JC002863.

Frank, D., D. Foster, I.M. Sou, and J. Calantoni (2015), Incipient motion of surf zone sediments, J. Geophys. Res. Oceans 120, 8, 5710-5734, DOI: 10.1002/2014JC010424.

Khezri, N., and H. Chanson (2015), Turbulent velocity, sediment motion and particle trajectories under breaking tidal bores: simultaneous physical measurements, Environ. Fluid Mech. 15, 633-650, DOI: 10.1007/s10652-014-9358-z.

Reungoat, D., P. Lubin, X. Leng, and H. Chanson (2018), Tidal bore hydrodynamics and sediment processes: 2010-2016 field observations in France, Coastal Eng. J. 60, 4, 484-498, DOI: 10.1080/ 21664250.2018 .1529265 .

Riaz, M.Z.B., S.-Q. Yang, and M. Sivakumar (2020), Simultaneous measurement of horizontal and vertical velocities and forces beneath a tidal bore, Coastlab20, IAHR, Zhoushan, China, 8 pp.

Yang, S.-Q., M.Z.B. Riaz, M. Sivakumar, K. Enever, and N.S. Miguntanna (2020), Three-dimensional velocity distribution in straight smooth channels modeled by modified log-law, J. Fluids Eng. 142, 1, 011401, DOI: 10.1115/1.4044183. 